\title{
An ecologist in mining -a retrospective of 40 years in mine closure and reclamation
}

\author{
N.J. Coppin Independent consultant, formerly Wardell Armstrong International, UK
}

\begin{abstract}
The author has been involved in mine waste reclamation and mine closure for 40 years. This paper charts a personal journey from the 1970s to the present day and considers how developments in the understanding of the science and of the regulatory, social and political changes that have occurred have influenced approaches to mine closure, reclamation and post-mining regeneration.

This is not just a retrospective; it also looks forward to the future, to the lessons still to be learned and where important challenges still remain: pats on the back reflecting short-term results rather than long-term sustainable function; design for closure, so often talked about but rarely taken on board meaningfully; what to do with a hole in the ground, open pits and quarries that present unique challenges and sometimes opportunities; social licence to operate and how community engagement is so important; re-inventing the wheel and the need for reclamation trials; when is a mine no longer a mine but closed, and how this uncertainty can frustrate the planned closure process; and who pays and the need to internalise the external reclamation costs.

In conclusion, it is noted that it is not just research and the knowledge gained and published that is important, but how this is applied and used in a practical way, in the real world of a life-of-mine and contractual environment with financial and management constraints and risks.
\end{abstract}

\section{$1 \quad$ Introduction}

I have been involved in mine waste reclamation and mine closure for 40 years. This paper charts a personal journey from the 1970s to the present day and considers how developments in the understanding of the science and of the regulatory, social and political changes that have occurred have influenced approaches to mine closure, reclamation and post-mining regeneration. The hope is that this will put a personal face on a subject that otherwise might seem quite abstract. However, this will not just be a retrospective; it will also look forward to the future, to the lessons still to be learned and where important challenges still remain.

Mine closure and reclamation involves interaction and cooperation between ecology, soil science, geochemistry, landscape design, land use planning and management, climatology, hydrology, civil and mining engineering, socio-economics and social science (and more, no doubt). There is a wide range of professionals who practise these disciplines, which means that there are many challenges to recognise and reconcile. It is important to recognise how each of these disciplines can work together to achieve successful outcomes - it is not just multidisciplinary, but interdisciplinary. The author has had the privilege of working with all these disciplines and has had the opportunity to learn from every one of them, and it is hoped that this has brought a wider understanding to the mine closure and reclamation process.

The public perception of the mining industry, and industry in general for that matter, is so often associated with many ' $D$ ' words:

- Destruction, devastation, despolation and damage: These are the common perceptions (according to some) of what the mining industry and its legacy are all about. Too often this has indeed been the case - the legacy of the industry is not always positive. Whilst shareholders and owners have 
benefitted from mining, and wider society benefits from using the commodities produced, the environment and local communities so often pay a heavy price.

- Degradation, dereliction: During the 1960s and 1970s, the awareness of derelict and degraded land increased. As the impacts on the environment and communities were recognised, government policies in Europe and North America began to address the problems.

As reclamation and restoration were becoming more widespread processes and as mineral planning (certainly in the UK) was starting to acknowledge the importance of afteruse and avoiding dereliction, there was much discussion about what was meant by the terms reclamation, restoration and rehabilitation. This was complicated by the frequent use of other similar terms such as renewal, redemption, regeneration and revegetation.

Bradshaw and Chadwick considered this in the introduction to their seminal work The Restoration of Land and for the purposes of the book took this definition:

"restoration is used as a blanket term to describe all those activities which seek to upgrade damaged land or to re-create land that has been destroyed and to bring it back into beneficial use, in a form in which the biological potential is restored." (Bradshaw and Chadwick, 1980)

Bradshaw (1997) had explored this earlier in the context of what can be achieved through restoration ecology. This is not just semantics; understanding what is meant by the terms in different contexts helps in understanding what it is someone is trying to aim at and what might be achieved.

At the time, the following broad definitions of the terms were generally accepted, and still are, although they are sometimes used interchangeably (and the meanings certainly overlap):

- Restoration: Returning land to something like its former state, use and condition, although it can often have a wider meaning, as defined by Bradshaw and Chadwick (1980). This may often be applied to short-term disturbance, such as strip mining or sand and gravel extraction, where a stratified deposit is removed and the layers/strata above it are returned 'over the shoulder' in the correct sequence.

- Reclamation: Often applied to derelict and abandoned land, including post-mining and post-industrial legacy, and to urban decay. Reclamation is a process of bringing land back from some damaged or degraded state into a new and improved state, with a beneficial use, not necessarily related to what was there originally.

- Rehabilitation: Similar to reclamation but often used within the context of transition from active mining - that is, land progresses from its original condition through mining and is then rehabilitated to a new state and beneficial use, without having become derelict or abandoned in the meantime.

- Regeneration: A broader term than reclamation, used to encompass the above along with socio-economic improvements and benefits for community cohesion. This is often applied to more than a single mine - to a region or community that was dependent on mining and has declined as a result of mine closures and rationalisation.

No doubt others will have different recollections and interpretations of these terms and their meanings. Note that there is a distinction between two starting points: the abandoned and derelict (legacy) condition versus the planned closure and decommissioning condition. The technical problems and the challenges to overcome them will be similar in both, as will the opportunities and objectives. However, the wider perceptions, processes and costs may be very different.

At this point, it is worth mentioning some other useful terms - the ' $A$ ' words:

- Afteruse: Once the initial enthusiasm for removing problems and improving landscapes through reclamation, etc., passed, the emphasis shifted towards having a specific afteruse in mind, particularly when spending taxpayers' money. An afteruse has to be beneficial - that is, it should 
have a value, whether economic (productive farmland or development potential) or intangible (such as recreation, nature).

- After care: Coined by Bradshaw (recorded in Bradshaw and Chadwick, 1980, but used by him before this), this term encompasses the essential maintenance of soil and vegetation needed to ensure its long-term biological function and return to a condition where the management required is similar to that of normal land in a similar use. It means that it is not sufficient to sow grass or plant trees so they are green for a year or so; they need a period of intensive management - reclamation is not just a one-off exercise that can be fitted within the standard construction contract 'defects liability' period. In the UK, an after care period of at least five years was usually required.

- Amenity: This is a dreadful term that was so often used to mean 'I don't know what I'm reclaiming this land to, but I hope that I can turn it green long enough to walk away and get away with it, because I have no obligations beyond this'. At best it meant an afteruse involving public access, passive recreation or even wildlife, but no specific objective or function. Fortunately, this term is not widely used now, except when qualified with a specific objective.

\section{$2 \quad$ China clay in SW England}

I started out as an ecologist with English China Clays (ECC, now Imerys) working on the reclamation of mining wastes in Cornwall during the 1970s. Having the very good fortune to work with Tony Bradshaw and his research teams from Liverpool University, it was exciting to be part of the early pioneering work on understanding how soil-plant systems develop on various mine and industrial wastes and modified landforms.

My role was an interesting one. As well as general ecological work for planning applications, I was the main liaison between the Liverpool research team and the 'landscaping section' of the company, which involved understanding what the research was finding out and translating this into practical landscaping and restoration methods on a large scale. This mainly involved hydroseeding of grass swards directly onto the steep conveyor-formed sand tips, which were inaccessible by any other means.

The early constraint was the nature of the tips - steep, loose-sided sand tips, with limited potential for any beneficial use. This was a legacy of the early planning conditions applied by Cornwall CC under advice from the Ministry of Agriculture - their priority at the time was to minimise the footprint of agricultural land taken by the tips (no matter how poor this land was) by maximising the tipping capacity - i.e., making the tips as steep and high as possible. The result was that the land around the tips, of low agricultural land classification anyway, became neglected and unused, and the tip landforms were effectively unrestorable difficult to vegetate and incapable of any meaningful use. Thus rehabilitation efforts were based on hydroseeding and green cosmetics, the only benefit being to the local rabbits and some reduction in wind erosion and dust nuisance to nearby residents.

A later study funded by the Department of the Environment on Landscaping and Revegetation of China Clay Wastes (Coppin, 1995) looked at not only reclamation techniques but also other approaches to the whole question. This study promoted a land suitability approach - taking a wider perspective and a strategic approach to land use and land capability across the claylands, which involved looking at long-term tipping requirements, availability of land and future land use. Whilst this may require greater land take for the tips, the result would be better long-term prospects with tip landforms that could be meaningfully rehabilitated to something useful. This was developed further by Cornwall County Council into the St Austell China Clay Tipping and Restoration Strategy (Cornwall County Council, 2000; Cornwall Council, 2013).

One of the main revegetation techniques used on the tip landforms was hydroseeding (hydraulic seeding by spraying a suspension in water of seeds, fertiliser, lime, organic mulch and often some form of crusting agent to hold it all down). This could be done from the bottom and top edges of the tip slope to reach the whole tip face, without requiring access. 
The results of this process were mixed and were susceptible to failures due to subsequent rainfall. But on the whole it worked well and enabled some form of grass-legume mixture to be established. However, it is a very expensive technique and required frequent maintenance visits to apply more lime and fertiliser.

For a while hydroseeding enjoyed some sort of mythical or magical reputation - a universal panacea to vegetating any sort of land, however poor, without the usual agronomical requirements. This was certainly not the case; it is not a replacement for conventional soiling and seeding but was often touted as such.

ECC was certainly a pioneer in developing hydroseeding techniques, the use of mulches and other ameliorants like digested sewage sludge. It became a fine art in the claylands, and maybe the results it achieved did appear magical.

The teams from Liverpool under Bradshaw were pioneers in land reclamation. From the initial work with NPK factorial experiments by John Handley and Bill Dancer, others including Dave Roberts, Rob Marrs, Richard Skeffington and Tony Kendle looked in detail at aspects of grass-legume sward development, NPK nutrition, nutrient cycling and balances and soil development on the very inhospitable sand and stent waste materials.

The work on China clay wastes was part of the wider research interests of Bradshaw's team, and it led to an understanding of the importance of early soil development and fertility in establishing a sustainable soilplant ecosystems on mine waste, quarries, colliery spoil and urban derelict land. Based on studies of both natural colonisation and revegetation of skeletal soils, a magic number of $900 \mathrm{khN} / \mathrm{ha}$ in the soil system turns out as being a minimum before dependence on legumes and nitrogen fertiliser was reduced and natural nutrient cycling worked. Bradshaw was a master at merging and combining lessons from all the various research projects he initiated.

ECC was also undertaking its own research alongside the academics:

- We investigated the use of low-maintenance grasses, mainly sourced from the amenity and sportsturf industry, when the difficulty of maintaining agricultural varieties became obvious. When you are seeding at $50 \mathrm{~kg} / \mathrm{ha}$ over all those hectares of tips, you become a major purchaser of seed mixtures. Finding the right ones, which survived in low-nutrient, acidic skeletal soils with no exchange capacity and were available in commercial quantities at reasonable cost, became a challenge.

- Similarly with legume species. We needed to find non-forage varieties of clovers, trefoils, alfalfa, etc., that did not have the demands of the usual varieties available.

- The natural vegetation of the upper elevations in the claylands is heathland. ECC was one of the pioneers in using heathland seedbanks salvaged from future tipping areas to revegetate tip areas to this type of semi-natural vegetation.

- The tips were very exposed and the establishment of trees became a priority, as an alternative to the usual hydroseeded grass swards.

The later work by ECC and Liverpool extended this to woodland development and large-scale heathland restoration. This led to projects with English Nature (now Natural England) to develop wide areas of the claylands for woodland and heathland as part of the long-term claylands strategy (Grigg et al., 1998; Natural England, 2013).

One of the main lessons that became apparent from this work throughout the 1970s was that establishing vegetation on mine dumps could be achieved successfully, and we learnt a lot about developing functional soil-plant systems. But in practice the results were often short term, with very narrow benefits and very expensive to maintain. What was needed was a broader approach to reclamation, based on land use and what we now recognise as ecosystem services.

At the same time as the work on reclamation, the value of derelict and contaminated sites for nature colonisation, as well as the study of metal tolerance in plants, was becoming recognised as a result of 
Bradshaw and workers at Liverpool. Old mineral waste sites, such as tailings from base metal and fluorspar mining and lime waste from the Leblanc chemical process, were unique ecosystems and refuges for species that were otherwise becoming increasingly short of suitable habitat.

\section{Quarry reclamation}

Working with Tony Bradshaw at ECC led to an opportunity to join his team at Liverpool for a Mineral Industry Research Organisation (MIRO)-funded project. The Environmental Advisory Unit at the University was one of the first groups to offer independent environmental consultancy on derelict and contaminated land reclamation and environmental impact assessment (EIA).

The MIRO project was a two-year contract to research and correlate published and practised techniques of establishing vegetation on disused workings and spoil tips associated with mineral workings and to prepare guidance for the minerals industry and regulators (planners) on practical reclamation techniques. There were two streams - one looking at quarries and open pit non-metalliferous mines and the other looking at metalliferous mines. The outcome was two books: Coppin and Bradshaw (1982) and Williamson, Johnson, and Bradshaw (1982).

This was one of the first attempts to bridge the gap between academic research on reclamation and practical solutions based on this science and to present the range of techniques available, with details of their application. It was a very exciting place to be for me professionally - not being particularly academic, but working with the industry to understand its needs and acting essentially as middleman or translator between two different worlds.

The environmental profession was only just beginning to become established, though ecologists were still seen as green campaigners and bunny-cuddlers more interested in idealistic activism and being antidevelopment. It was a very different professional world to the one we take for granted now. There were no professional bodies, and the only way to be taken seriously was to be an engineer, surveyor or landscape architect. The Landscape Institute was the only body that considered admitting ecologists, and it was quite visionary in this respect. However, ecology was always the Cinderella within that institute, so when the growing band of professional ecologists decided to buy suits and ties and become an institution, they formed their own professional body - the Institute of Ecology and Environmental Management (IEEM) which has gone from strength to strength. The IEEM was granted a Royal Charter in 2013.

\section{$4 \quad$ Coal and slate in Wales}

The next incarnation of my work was consultancy, working with engineers involved in large-scale reclamation schemes on colliery spoils, slate mines and metal mines, mainly in Wales. The Aberfan disaster in 1966 was a major wake-up call to local authorities and the industry about tip safety, environmental degradation and their effects on communities. This was the start of the regeneration of mining communities, reinforced by the rapid and devastating restructuring of the UK coal industry in the 1980s. Initially the main objective was tip safety and removal of dereliction. This then evolved into regeneration and creating opportunities for regeneration and economic reinvention.

What I found when I started in 1981 was a process that, despite the best intentions, often converted one form of derelict land into another at great public expense. The objective was mainly cosmetic, and tip reclamation was essentially a civil engineering process - stabilise the tips, make safe the mine shafts, flatten the tops to 1:100 slopes suitable for development (which often never happened), put in drainage and grade the side slopes to 1:3. All very safe, but very angular and engineered. The whole area was then liberally covered with chicken manure and seeded - it looked great, bright green, for a year or so, then went brown and progressively died off until the surface was bare and eroded again. These became prairies, the only afteruse being a couple of years of poor grazing for any local person with a horse and for the ubiquitous woolly maggots (sheep). 
To be fair, some sites were later developed as industrial estates and business parks, as part of the economic regeneration of the area. The last of the Garden Festivals was held at Ebbw Vale, as part of the large-scale reclamation in the valleys.

The technical challenges were still significant, not all of the ecological lessons had been learnt. We knew about compaction in regraded materials such as colliery spoils, about getting organic matter in and developing soil-forming materials. However, getting these taken on board within the engineer-dominated contractual environment of reclamation was not easy. Geotechnical engineers think that compacting soils is a good thing - it does not allow any water to get in. Landscaping involved spreading so-called topsoil and planting a few 'lollipop' trees. Then along comes some landscape ecologist who tells them that they have to rip the surface and let the water in, so the plants will survive.

Anything slightly muddy and coloured brown constituted topsoil, unfortunately, no matter how rubbish it was. Chicken manure was a wonderful and magical alternative - turning the surface brilliant green long enough for the contractor and consultant engineer to get off-site and get paid. No one was interested in long-term function or use, and capital expenditure under Derelict Land Grants did not cover any maintenance or after care.

Progressively, ecologists and landscape architects began to be involved as well. Through the 1980s the emphasis on good structural landscape and sustainable vegetation became more significant. The work of the local authority ecologists and landscape architects working for the New Town Development Corporations enabled great improvements to be made.

\section{$5 \quad$ Bioengineering}

During this period I took a significant diversion for a while. I undertook a project for the Welsh Office looking at why road cuttings and embankments never seemed to successfully vegetate, and what to do about it. At the same time, the Construction Industry Research and Information Association (CIRIA) was beginning to get interested in how vegetation could complement novel geotextile engineering materials in situations like dam spillways.

This led to an extensive research project, through CIRIA, to review how vegetation can serve an engineering function, in addition to any landscaping or ecological functions. This involved looking at vegetation in a new way, in bioengineering terms, combining an understanding of engineering principles with knowledge of vegetation and its interaction with soil, water and climate.

Much of the basic field research and background work for these ideas came from establishing vegetation and erosion control on road cuttings in mountainous areas of Europe, remote areas of the USA and the difficult slopes in Hong Kong. European countries, mainly Germany and Scandinavia, had long traditions in bioengineering, out of necessity - the problems they were solving were inaccessible and remote, so they had to rely on locally available materials (such as willows) and low-technology (men with shovels). The USA was taking the problems of soil erosion very seriously, and again local materials and simple technology was required in wilderness areas.

This exciting project required the development of a framework for suitable approaches, design, construction, establishment, maintenance and contractual aspects. The scope included vegetative methods for slope stabilisation, erosion control, watercourse and shoreline protection, shelter, noise reduction, surface protection and trafficability (Coppin and Richards, 1990).

Again, I found myself in an intermediary role, working across disciplines - geotechnical and hydraulic engineering, ecology, soil science, horticulture - each with its own conceptual frameworks, languages and cultures. The trick was mainly finding the common language and finding where the disciplines fit. This also meant understanding and communicating the ecological principles required for revegetation on engineered and skeletal substrates, in an environment that was more accustomed to horticultural and landscaping approaches (Coppin and Styles, 1995). 


\section{$6 \quad$ Mine closure planning in Europe}

Readers who have stuck with me this far will perceive a change in tack at this point. I shall be moving away from ecological restoration and techniques and turning to the wider issue of mine closure planning and how this fits with the mining process and regulation in the UK and other jurisdictions.

In the UK, mine closure planning was and still is the regulatory responsibility of the Mineral Planning Authorities (mainly County Councils in England and Wales). This system has ensured that restoration and reclamation of mineral sites was an integral part of the planning approval (i.e., permitting) process, along with EIA. Restoration and reclamation 'conditions' on planning permission go back to the late 1960s and early 1970 s and became progressively less naive and more robust over time. EIA of course became a formal part of the planning process much later (in 1988).

This planning regime could apply to new sites and extensions to existing sites, but mining and quarrying is often a long-term activity, so in the UK there was a mixture of long-standing sites with few, if any, closure requirements, together with newer sites operating to much stricter requirements. In 1991 the Planning and Compensation Act began the process of retrospectively applying modern conditions on old planning permissions, and periodically reviewing these (so-called ROMPPs).

Planning permission goes with the land, not the operator, so it is relatively easy for an operator to quietly slip away (go bust) and leave the reclamation conditions for a subsequent owner. An example of how this can happen is at Wheal Jane, where the mining company closed without fulfilling the reclamation conditions. The conditions still apply, however, and have to be discharged by the new owner of the site.

Yet the UK has resisted the move to require reclamation bonds or sureties, relying instead on the planning system and the fact that the majority of quarries are operated by larger companies with longer-term horizons with respect to reputation and future permissions.

Elsewhere in the European Union (EU), the permitting process is different. The European Community (EC) landfill directive and subsequently the mining waste directive of 2006 created a fairly consistent Europewide playing field. Similarly, the Integrated Pollution Prevention and Control directive of 2008 has driven the permitting process towards minimising long-term pollution liability and introducing requirements for environmental liability risk assessments for long-term waste repositories such as mine wastes. Mine closure in many countries is much more aligned to the pollution and risk management regime than the land use planning regime of the UK. Nevertheless, the UK has largely complied with the requirements under these EC directives by adding regulations to existing legislation.

In Europe, mine closure technical and procedural guidance was drawn initially from North America. The first guidance that I came across, which guided much of our initial approach, was the Ontario Guidelines (Ontario Ministry of Northern Development and Mines, 1991). This was the basis for one of the first detailed and comprehensive mine closure plans produced in Europe, for Galmoy Lead/Zinc Mine near Kilkenny, Republic of Ireland, in 1993. This closure plan was prepared before mining was even permitted, as part of the EIA and planning application for the mine, and was examined in detail at the Public Enquiry; planning permission was subsequently granted by An Bord Pleanala in 1994.

The Galmoy Mine Closure Plan considered not only the approach to and costs of final planned closure, but also premature closure for each year of the mine life. This resulted in a year-by-year profile of mine closure liability, which could then be covered by a combination of an insurance guarantee and an accumulating levy on production into an escrow fund.

More-specific mine closure guidance was produced by MIRO in July 1999 (SRK, 1999), which considered the process of closure planning. Mine closure was examined in some detail as part of the Mining, Minerals and Sustainable Development project, and a number of technical reports and working papers were published (MMSD, 2002). The International Council on Mining and Metals later published guidance on financial assurance (Miller, 2005) and a mine closure toolkit (Matrix+ Consulting, 2008). These all affirmed the approach to and process of mine closure as a fundamental part of the mining process, leading towards 
what environmental economists call 'internalisation' of closure, whereas historically it was always an 'external' cost.

\section{$7 \quad$ Eastern Europe}

In 1989 I joined Wardell Armstrong (WA). In addition to working on land reclamation and regeneration in the UK, WA had a much more international profile, with involvement in World Bank and the UK Department for International Development projects in Eastern Europe - reclamation and regeneration following transition of the former communist economies after 1991. Privatisation of the mining industries in many countries led to similar economic and community breakdown as had been experienced in the UK in the 1980s.

In contrast to the work in Wales, the emphasis was on economic and social regeneration as well as physical and biological reclamation. Expertise developed in the UK in dealing with the reclamation of former mining areas was applied to help countries such as Poland, Bulgaria and Romania restructure their mining industries and deal with the legacies.

Under the auspices of the World Bank, we also assisted with new mining codes and environmental management in the mining industries, improving regulatory regimes and institutional capacity.

The failure of the tailings dam at Baia Mare in 2000 and the subsequent release of cyanide into the Tisza River, part of the Danube catchment, affected many states - a transboundary disaster. This led to a reappraisal of risk from old mining remains, especially tailings dams, throughout the basin in Romania and Hungary. WA was involved in much of this work and in safety works following the Baia Mare incident itself.

At this time, East European research on reclamation was similar to what had been done in the UK. However, they had to contend with many different situations, such as large-scale lignite strip mining. I recall that whenever you met a reclamation engineer, they were desperate to find out more about what we were doing and to exchange ideas with western experts. The main difference between what they did and what we did was not intellectual - their science was just as good as ours - it was economic: they had no money to do anything. The state's attitude to public risk from mining was often ambiguous, particularly as the state-run mining sector was usually responsible for the problem and the new state administration was bearing the costs.

\section{Former Soviet Union}

The former Soviet Union has a very different regulatory regime, still based on the former Soviet model, albeit much extended and improved. The basis for mine permitting is predominantly the Subsoil Use Contract, which is quite prescriptive.

The reclamation process is similar to that in Europe, North America and Australia, though involving a clear emphasis on two distinct stages: technical reclamation followed by biological reclamation. However, there has not yet been much recognition of community and social reclamation.

Under the Kazakh Subsoil Use Law, renewed in 2010, there is a requirement on 'termination of subsoil operations' that 'all production facilities be brought to a condition ensuring the safety of the life and health of the population and environmental protection'.

Each mining operation is required to enter into a Subsoil Use Contract, which is the main licensing and mine permitting instrument. This contract includes specific requirements for each mine, including the establishment of a Conservation or Abandonment Fund as well as subsoil and environmental protection. But this only covers the mining operation itself, including any waste rock dumps. It does not extend to the processing plant and tailings management facility, which are licenced separately. However, in line with international practice, these facilities are now usually included in a mine closure plan.

The Subsoil Use Contract usually stipulates that the Abandonment Fund should accumulate in a special deposit account at a rate of $1 \%$ of the mine's annual expenditure. The Fund can only be used with the 
consent of the competent authority - the Ministry of Industry and New Technologies and the Ministry of Environmental Protection.

The Subsoil Use Law also defines mining wastes, such as waste rock and tailings, as 'man-made mineral formations' and as such are potential assets that might be re-processed sometime in the future. They are thus classed as stockpiles and not subject to closure in the same way as is dealt with internationally, such as under the EU Mine Waste Directive.

There are several anomalies with the Kazakh approach to regulating mine closure:

- The Subsoil Use Law only covers the mining operation, usually up to the run of mine stockpile, and related mining and waste management facilities. It does not cover the concentrator and other industrial facilities, including the water management, tailings management facility (TMF) or heap leach areas, which are licensed separately as industrial plants. Thus the obligations for closure and associated funds only apply to part of the operation; other parts, particularly the TMF, have no such requirement. This splits the responsibilities for a typical mining and concentrating operation, along with the associated liabilities, into two separate regimes.

- The meaning of 'termination of subsoil operations' is not defined, so when the implementation is required is not always clear, which can be confusing when the closure is not planned. At what time does it apply to a long-term stockpile of 'man-made mineral formation' (tailings) for example?

- The amount of the Fund is determined by the mine's expenditure and is not related to the potential costs of closure, remediation and long-term regeneration. Thus there is no requirement for the Fund to be matched to the actual anticipated costs, or to anticipate early closure or abandonment, before it has accumulated to a sufficient size.

- There is only provision for technical closure and rehabilitation of the land surface. There is no provision for social closure and post-mining economic regeneration.

\section{Influence of the Equator Principles}

In 'the West', regulation of the mining industry in almost all states means that there are consistent mine closure requirements. But in transitional and developing economies a wide variety of regulatory regimes cover mine closure, many of which are rudimentary.

The World Bank has done much to improve governance and legislation for the mineral sector in many regimes, with mining codes and associated environmental and social regulations. This is driven by a desire to enable foreign direct investment in these countries and to secure mineral supply for the developed countries, but with the overarching need to ensure that this does not lead to environmental and social degradation.

Over the last decade, the Equator Principles (EPs) have made a significant difference to the implementation of mine closure planning for projects in almost all jurisdictions - resulting in a much more level playing field. This applies to the whole range of environmental and social issues, not just closure. There is not time or space to go into any depth on the EPs here, but a brief description of them follows.

The EPs are a credit risk management framework for determining, assessing and managing environmental and social risk in project finance transactions. The 10 principles are given in Figure 1. Project finance is often used to fund the development and construction of major infrastructure and industrial projects. The EPs are adopted by financial institutions and applied where total project capital costs exceed US\$10 million. They are primarily intended to provide a minimum standard for due diligence to support responsible risk decision making.

The EPs are based on the International Finance Corporation (part of the World Bank) Performance Standards on social and environmental sustainability and on the World Bank Group Environmental, Health, 
and Safety Guidelines. Other codes, such as the Performance Requirements of the European Bank follow similar lines.

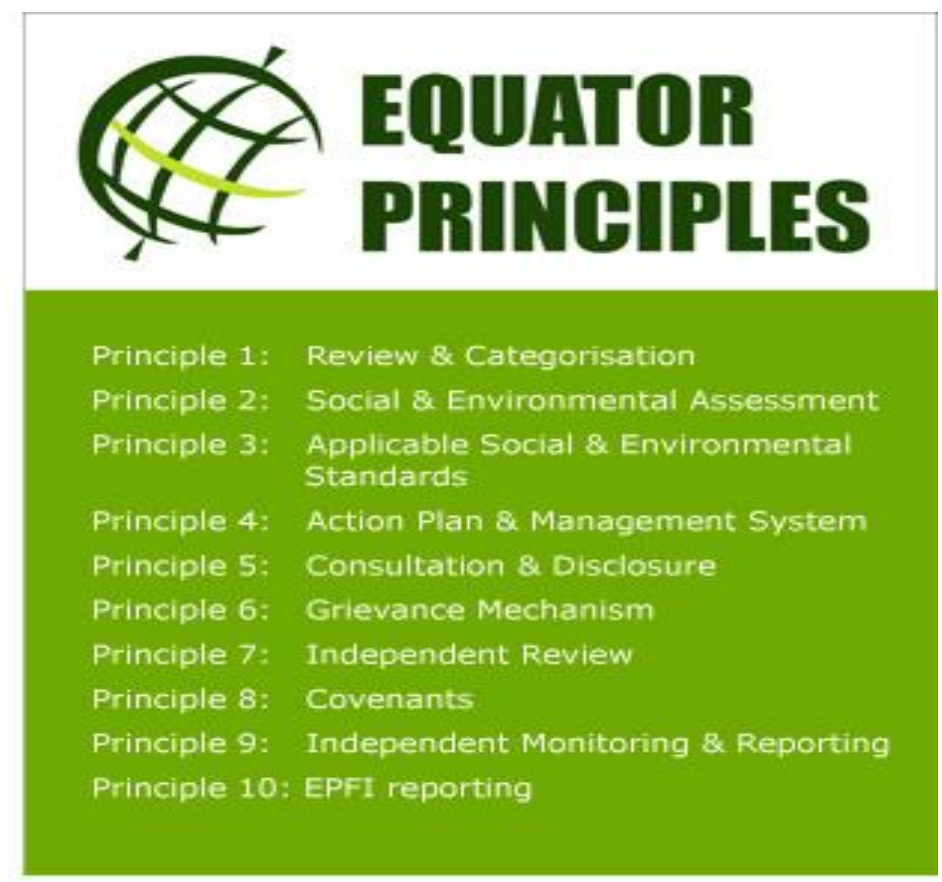

Figure 1 Summary of the Equator Principles (see www.equator-principles.com)

Equator Principles Financial Institutions, of which there are currently 78, commit to not providing loans to projects where the borrower will not or is unable to comply with their respective social and environmental policies and procedures. This includes mine closure.

What is fascinating is that one of the most influential and powerful means of raising standards of environmental and social management within the mining sector in developing and transitional states is not regulatory and does not even involve governments and legislators directly. It has come through the institutions that provide the majority of the finance for major projects (mainly development and commercial banks). This in turn is driven by public opinion and the high-street customers of these institutions. In my opinion, this is the most significant driver outside the developed states of the EU, North America and Australia/NZ. This is perhaps not surprising, as governments are notoriously bad and slow at responding to international pressures. As the saying goes, 'grab a man by his wallet, and his heart and mind are sure to follow!' (Note - the term 'man' is meant in the generic or collective sense of a man or woman and does not imply any difference in attitudes or response attributable to gender.)

\section{Challenges for the future}

This paper has touched on a wide range of issues, not always connected or logical, but reflecting the many influences on one person's career. I will now outline a number of thoughts and challenges for the future, not really as a conclusion but because they are in my head and may stimulate discussion.

\subsection{Pats on the back}

There are many reclamation award schemes, certainly in the UK. Whilst some of these are very worthy, many are only mutual pats on the back - and by their nature are based on short-term results. As can be seen from the early parts of this paper, you can grow almost anything anywhere in the short term, but achieving long-term sustainable benefit is more difficult. We need a better framework for long-term sustainable and beneficial uses that pay for themselves, combined with sound objectives and good success criteria. 


\subsection{Design for closure}

This is often talked about but rarely done. It is inevitable that mine design starts with the economic exploitation of an ore body and extraction of the desired minerals and that this will dictate the fundamental process of mining and mineral processing. The environmental and social impact assessment process now means that this is usually done with much less impact or risk. However, design for closure still does not really happen. The mine closure process still starts with the engineer saying: 'Here is the mine/pit/dump/tailings facility I've designed (albeit with the environment in mind), now over to you to work out how to close and reclaim it'.

We need to develop ways of shifting this thinking to something along the lines of: 'Okay, so we will have a mine and there are only certain ways that it can work and be profitable, but at the end of the mine's life we would like this/that opportunity for afteruse potential, so how can we design the mine to enable this to happen?' There is no doubt that we have made progress in this direction, but there is still a long way to go.

For many years I have advocated a land suitability approach - design the mine with the new use in mind, informed by the concept of land capability. The idea of land use capability classification, based on fitness for use, is well understood; it should be easy to turn this around to use the classification criteria as design objectives. This means that we can design with flexibility for suitability for a range of uses, without having to worry too much in the early stages about specific afteruses. As is often said - mining is a long-term exercise, so it is difficult to predict what requirements, opportunities or uses might be appropriate many years or decades in the future.

The ecosystem services approach also has potential to be a useful tool in mine closure planning. This could give us other ways of thinking about afteruse - not just for landscape or function but for the services (both monetary and intangible) that the new post-mining ecosystem should provide.

\subsection{What to do with a hole in the ground?}

This question has been asked many times. Pearman (2009), in 101 Things to Do with a Hole in the Ground, gave a good range of possible answers and stimulated many ideas. But realistically, for every one of those 101 there are maybe 1,000 other holes that have no potential (there are 4,000 in Blackburn, Lancashire alone).

Of course, there are many instances where the geology and the mining plan means that backfilling can be integrated into the scheme, without much additional cost. But for many open pits and underground workings, backfilling means double handling and substantial loading and haulage costs, after the pit is exhausted.

I have reviewed many mine closure plans where a statement along the following lines is made: 'The cost of backfilling the waste into the open pit after mining ceases is uneconomic, so the pit will remain', sometimes with an attempt at grading of the upper benches. This sort of statement must be preceded by one or more of the following thoughts:

- I haven't a clue what we could do with it anyway - who needs a hole out here in the middle of nowhere?

- If we did backfill and restored the pit, the land would not be usable for anything anyway, so why do it?

- There is still ore at the bottom, and if the mineral price goes up then it will be economic to exploit, so we mustn't sterilise it.

- If we include the cost of backfilling/reclamation in the discounted cash flow, the project would be uneconomical and won't get funding, so we'll leave it out as an external cost.

- There is no pressure from the regulator or the bank to reclaim the pit. 
- There is not enough material to restore the pit; we would have to import it (at great expense or with resulting impacts elsewhere).

These may be perfectly valid thoughts, but they do leave this question: should the mine be backfilled and restored to a sensible landform, because we should aim to leave as small a long-term liability as possible?

The usual practice is to just leave the pit shell (if an open pit) with the final benched landform, based on the economic strip ratio and geotechnical stability. At the very least, I believe that the final pit shell should be designed to enable some form of reclamation - i.e., with shallower slopes and no benching - to reduce weathering, erosion and maybe geochemical changes.

\subsection{Social licence to operate}

Mine closure is an important aspect of obtaining, and retaining, your social licence to operate - at a project, corporate and industry level. We are getting much better at integrating social and community aspects more fully and consistently into the mine closure process, but there is still a long way to go.

If we take care of the technical and biological reclamation, and generate a new land use, it may be true that the community will benefit and will take care of itself. However, for many mines the following questions may need to be asked:

- At the end of mining, is the community the same, demographically and economically, as when (or before) we started?

- Are there alternative livelihoods available, and will the skills learned during mining be transferrable to new livelihoods with sustainable markets?

- If the project involved inward migration of workers and skills, will they simply migrate outward again when the mine closes? If so, where?

Two factors seem to be critical in these questions: timescale and remoteness. The longer that a mining complex or series of mines has operated, the more established is the community it supports. And if a community is remote, the timescale for it to be established is longer.

\subsection{Reinventing the wheel}

At many mine closure and reclamation conferences you hear papers in which the authors have repeated investigations that you know were done some years ago or in a different country. Why are the lessons learned from the past, or from different geographical areas, not better researched and taken account of? Is it laziness and failure to do proper, in-depth literature research and apply this to a new situation? Is it because we are parochial and assume that solutions researched elsewhere are not relevant to us, because our situation is different? Or is it because university libraries clear out their shelves of books and journals older than 20 years, to make room for new ones, so published research beyond this is effectively inaccessible?

Having said this, it is also important that at a new situation there are proper local trials carried out, to confirm, practise and fine-tune the solutions for local circumstances. There is a tricky balance between reinventing the wheel and repeating basic research, or making basic mistakes because no proper trials were done first.

\subsection{When is a mine no longer a mine, but closed?}

In an ideal world, a mine is explored, planned, permitted, commissioned, operated and ultimately closed at the end of its economic life, in a logical and smooth manner, with everything following the plan. Most greenfield mining proposals assume that this is how it will go, and the mine design and environmental permitting is prepared on this basis. 
The reality can be very different, for a number of reasons:

- Most (though not all) mines closed recently or being closed now were commenced many decades ago and were not designed for closure, and many have no closure plan or financial provision.

- When a mine closes, it is rare that the initial developer or proponent is still the operator; there is often a chain of owners, particularly as profitability falls and new investment is needed. The initial mine proponent may have had good intentions and sustainability policies, and high operating standards, but at the end of the mine life this may be a different story.

- This leads to an important question - to what extent can a mining company be held responsible for the conduct and liabilities of its successors, notwithstanding what any sale agreements or permits may say? At the moment, it seems very little. Even a responsible mining company can leave its potential liabilities behind if they divest the asset.

- A mining company acquiring an existing or brownfield asset will want to protect itself from inherited past liabilities, so these will often be excluded. Past liabilities often pass to the state.

- The main closure costs and liabilities occur when a mine operation is becoming exhausted, has lower revenue and is least able to pay for them. So unless a tangible cash fund has been accrued, or the mine operator has sufficient corporate resources, there will be no resources for closure. Provision for closure should be linked as closely as possible to profitability at different stages during mining.

- Commodity prices go up and down, and thus curtail or extend the life of a mining operation and the financial viability of the mine operator. A sudden fall in commodity prices can lead to a rapid decline in the solvency of the mining company and thus very sudden unplanned closure and abandonment. In these cases the Mine Closure Fund or guarantee has to be invoked, if there is one, and it has to pick up the pieces from an unplanned closure.

- Such sites may still have a potential value and thus be dormant, or on care and maintenance, so full closure is not undertaken. A new operator may acquire the asset and develop it, subject to prices going back up or new technology becoming available. Thus the point at which we can say that a mine is exhausted and is therefore of no further economic value is not a straightforward point in time that is easy to define. It depends on a range of economic, geological and technological factors and may be a long drawn-out process.

- When a new mining licence is issued there is an opportunity to update and extend closure requirements in the permit. But this still has to contend with the uncertainty of when the mine will be at the end of its useful life?

Under most regulatory regimes, the mine closure process and financial provisioning are not good at dealing with these uncertainties and unpredictable situations, which introduces an element of risk. How is this risk best managed by companies and regulators?

\subsection{Who pays for closure, reclamation and regeneration after mining?}

Most often, and historically, closure costs have been what economists call 'externalities' - they are external to the project economics. Thus it is the local community and society that pays - as the victim of dereliction, contamination, pollution, loss of ecosystem services and natural ecological and life support systems, hazards and so on. Any cost associated with removal or regeneration of these is borne by the state - or more correctly the taxpayers, who are the wider society in which the problems occur. It is not often the same society (region or country) that benefitted from the products of mining in the first place.

Legislation and modern enlightened approaches to environmental responsibility and sustainability have sought to 'internalise' these externalities - that's economist-speak again. This means that the true cost of mining, including closure and post-mining regeneration, is borne by the producer. The producer either 
accepts a lower profit and thus dividend, or it passes the additional costs on to the customers or consumers of the products, which is where the cost should properly be borne.

For this internalisation to work there has to be a level playing field, which is difficult in a world commodity market. If consumers can simply switch to cheaper sources of a commodity, such as from a country where environmental protection and mine closure costs are not internalised, then this will drive the producers to do the same unless there are technological, infrastructure or other advances that offset the additional costs.

Many developing economies are eager to secure foreign direct investment and economic development of their natural resources and thus are tempted to keep environmental obligations and constraints to a minimum.

Similarly, many developed economies that have put in place strong environmental regulations are accused of simply exporting their pollution and environmental degradation to other countries with lower standards. This can only be countered with a wider responsibility for sustainability, and awareness of consumers and downstream users, throughout the supply chain, thus levelling the playing field.

How can mine closure and regeneration costs be built in to the project costs? This is still a thorny area and there are different approaches, not all of which can work. There are a number of instruments available, which I have put into three main categories:

- The company's own resources or revenue from production: A larger mining company will also have corporate resources from which to fund closure; these companies are also more conscious of their continuing obligations and reputation, and their ability to secure future mining licences, so will act with greatest responsibility.

- Bonds and guarantees secured through a bank or insurance policy: There are popular mechanisms, as there is no capital tied up, and expenditure (premiums) is revenue-based. These are useful instruments to guard against unplanned closure and default. However, there are two major shortcomings - there is no actual cash fund set aside for future or unplanned closure, and they are only effective for as long as someone is paying the premiums. When an asset is transferred, the bond has to be taken over by the new owner, who may not be able to secure the bond or service it fully.

- Cash funds, as either a single deposit or an accumulating fund, which are held in escrow: Single deposits are not popular because they increase the capital requirements of the project significantly and are expensive. Accumulating funds are more sustainable, but there will be a shortfall in the size of the fund in the early years. Accumulating funds are usually based on a production levy or, in the case of Subsoil Use Contracts, on the mine expenditure.

In all cases the two important aspects to ensure are these:

- The fund or security must be ring-fenced from the company assets and only usable for the purpose intended. It is not acceptable to simply accumulate the 'fund' as a liability on the balance sheet. It must be tangible and accessible by whoever is picking up the tab for the liability (if not the company, this is usually the local or central state authorities).

- The size of the fund or security must be linked to the cost of closure and regeneration, including early and unplanned closure.

\section{Conclusion}

This journey began with technical and ecological stuff - how to do reclamation, and progressed to the mine closure process and how this works in various regulatory regimes. It also charts a personal journey as a career, which reflects the evolution of ecology and particularly reclamation ecology as a respectable profession. 
What should have been obvious from this is that I am no great researcher or academic. My contribution to the advancement of fundamental knowledge on reclamation has been very small. What I have focussed on is how the knowledge of others, and from the wider ecological and engineering community, can be applied and used in a practical way - how we can get better bioengineering, mine closure and reclamation by getting the basics and simple processes right. This means applying knowledge in the real world of a life-ofmine and contractual environment, with a variety of financial and management constraints and risks.

\section{Acknowledgements}

I owe a great debt to Tony Bradshaw, who was my mentor for many years.

Many others have played a significant part in what I have learned: Mike Johnson - legend (not just for curries); Derek Owen and subsequently Colin Grigg (ECC); Ray Lewis and Ivor Richards (Robinson Jones Partnership); Mervyn Bramley (CIRIA); and Eric Hassall and Ken Bate plus many recent colleagues at Wardell Armstrong.

\section{References}

Bradshaw, A.D. (1997) What do we mean by restoration? In Restoration Ecology and Sustainable Development, K.M. Urbanska, N.R. Webb and P.J. Edwards (eds), Cambridge University Press, Cambridge.

Bradshaw, A.D. and Chadwick, M.J. (1980) The Restoration of Land, Blackwell Scientific Publications, Oxford.

Coppin, N.J. and Bradshaw, A.D. (1982) Quarry Reclamation - the establishment of vegetation in quarries and open pit non-metal mines, Mining Journal Books, London.

Coppin, N.J. and Richards, I.G. (1990) Use of Vegetation in Civil Engineering, CIRIA \& Butterworths, London.

Coppin, N.J. (1995) Landscaping and Revegetation of China Clay Wastes, Project undertaken by Wardell Armstrong, Department of the Environment, London.

Coppin, N.J. and Styles, R. (1995) Ecological principles for vegetation establishment and maintenance, in Slope Stabilisation and Erosion Control, A Bioengineering Approach, R.P.C. Morgan and R.J. Rickson (eds), E \& F Spon.

Cornwall County Council (2000) St Austell China Clay - Tipping and Restoration Strategy, Cornwall, UK.

Cornwall Council (2013) Technical Paper M1 - China Clay: Minerals Plan within the Proposed Cornwall Local Plan, Cornwall Council.

Grigg, C.F.J, Coppin, N.J., Box, J. and Davies, I. (1998) Re-creation of heathland habitats in the China Clay mining area of Cornwall, in Landreclamation - Achieving Sustainable Benefits, in Proceedings of the Fourth International Conference of the International Affiliation of Land Reclamationists, H.R. Fox, H.M. Moore and A.D. Mclntosh (eds), Nottingham, UK, 7-11 September 1998, A.A. Balkema, Rotterdam.

Matrix+ Consulting (2008) Planning for Integrated Mine Closure: Toolkit, International Council on Mining and Metals, London. Miller, C.G. (2005) Financial Assurance for Mine Closure and Reclamation, International Council on Mining and Metals, London. MMSD (2002) Mining, Minerals and Sustainable Development. Breaking New Ground, Earthscan Publications Ltd., London.

Natural England (2013) China Clay Woodland Project, viewed May 2013, http://www.naturalengland.org.uk/regions/south_west/ourwork/chinaclaywoodlandproject.aspx.

Ontario Ministry of Northern Development and Mines (1991) Rehabilitation of Mines - Guidelines for Proponents, Sudbury, Ontario.

Pearman, G. (2009) 101 Things to Do with a Hole in the Ground, Post Mining Alliance, Eden Project, Bodelva, UK.

SRK (1999) Steffen, Robertson \& Kirsten (UK) Ltd. A Technical Framework for Mine Closure Planning, prepared for Mineral Industry Research Organisation, UK.

Williamson, N.A., Johnson, M.S. and Bradshaw, A.D. (1982) Mine Waste Reclamation, Mining Journal Books, London. 
